\title{
An Inquiry Into the Statistical Basis of a Conclusion Concerning Sex Differences
}

\author{
George W. Frasier.
}

Director of Rescarch, State Normal School, Cheney, Washington.

HOR many years psychologists and educators have been inter$F$ ested in the problem of sex differences in relation to education. Studies dealing with different phases of this subject have been made in America and several European countries. These studies have lacked unanimity of conclusion, however, and have not established laws that psychologists and educators have been ready to accept. It is true that numerous conclusions have been made which have been accepted by many and quoted widely; but at the same time these have been disbelieved and rebutted by others. This article is concerned with the statistical basis of such a conclusion.

In I9I 5 Yerkes, Bridges and Hardwick published a monograph explaining the derivation and standardization of $A$ Point Scale for Measuring Mcntal Ability. The authors of the scale were convinced that their data showed some pronounced sex differences. The following conclusions are quoted from their monograph $:^{I}$ "These two sex groups, although not large, exhibit surprisingly pronounced modes, that for the girls being constituted by the 55 point class-and that for the boys the 65 point class. It appears from these distribution curves that at ten years of age the difference in mental capacity between boys and girls is so great that its neglect would inevitably lead to unfair evaluation of individual results," and "We are fully convinced, however. that the accurate determination of norms for the sexes is eminently desirable, and we suspect that at certain ages serious injustice will be done to incividuals by evaluating their scores in the light of norms which do not take account of sex differences."

Two very interesting statistical points are involved in the method by which this conclusion was reached, (I) the wisdom of using the mode as a measure of central tendency and (2) the validity of conclusions drawn on so few data.

The distributions referred to in the above quotation are shown in Table $I$, Parts $I$ and 2.

\footnotetext{
A Point Scale for Measuring Mental Ability. Page 63.

${ }^{2}$ Idem. Page 73
} 
TABLE No. I

Frequency tables of Point Scale scores for the English speaking. ten-year old children in School "B."

\section{PART I} Ungrouped Data.

Boys

$\begin{array}{ll}44 & 39 \\ 48 & 40 \\ 52 & 47 \\ 54 & 48 \\ 54 & 50 \\ 56 & 51 \\ 58 & 54 \\ 60 & 55 \\ 61 & 56 \\ 63 & 57 \\ 65 & 58 \\ 65 & 59 \\ 65 & 59 \\ 66 & 59 \\ 66 & 59 \\ 66 & 60 \\ 66 & 60 \\ 67 & 60 \\ 67 & 66 \\ 69 & 67 \\ 73 & 67 \\ 74 & 72 \\ 76 & 72 \\ 78 & 74 \\ 84 & 77 \\ & 77 \\ & 79 \\ & 80\end{array}$

PART 2 (For Fig. A)

Distribution Used by Yerkes. Interval.

35-39

40-44

$45-49$

$5^{0-54}$

55-59

$60-64$

$65-69$

$70-74$

$75-79$

$80-84$
Frequency.

Boys. Girls.

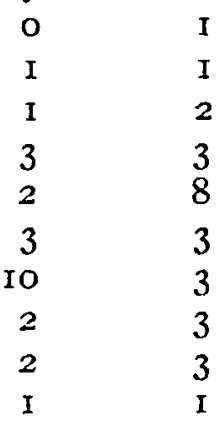

PART 3 (For Fig. B)

$$
\text { Interval. }
$$

$38-42$
$43-47$
$48-52$
$53-57$
$58-62$
$63-67$
$68-72$
$73-77$
$78-82$
$83-87$

Frequency.

Boys. Girls.

$\begin{array}{rr}0 & 1 \\ \mathrm{I} & \mathrm{I} \\ 2 & 3 \\ 3 & 4 \\ 3 & 8 \\ \mathrm{IO} & 3 \\ \mathrm{I} & 2 \\ 3 & 3 \\ \mathrm{I} & 2 \\ \mathrm{I} & 0\end{array}$

\footnotetext{
PART 4 (For Fig. C)
}

Size of interval increased to eight.

Interval.

$$
\begin{aligned}
& 35-42 \\
& 43-50 \\
& 51-58 \\
& 59-66 \\
& 67-74 \\
& 75-82 \\
& 83-90
\end{aligned}
$$

Frequency.

Boys.

Girls.

$\begin{array}{rr}0 & 2 \\ 2 & 3 \\ 5 & 6 \\ \text { I0 } & 8 \\ 5 & 5 \\ 2 & 4 \\ \text { I } & 0\end{array}$


These figures were taken from data found on page 53 of the monograpl, grouped according to directions on page $6 \mathrm{r}$, and express the frequency of scores on the point scale for 53 children, 25 boys and 28 girls. The "surprisingly pronounced modes" can be seen at the " 55 point class" for the girls and the " 65 point class" for the boys. It is evident from these data that the central tendency for the girls is ten points below that for the boys: hence the authors' generalization concerning sex differences. It is also obvious that this conclusion is based upon a modal value concerning which Rugg says ${ }^{3 " \prime}$ This specific modal value-depends, within a certain range over the scale, upon the size and position of classintervals." Acting upon Rugg's suggestion it is our purppse to change the size and position of the class-intervals and observe the result upon the modes. In the table of frequency given in Table $I$, Part 2 the class interval is five. The 55 point class, quoted from the monograph, is made up of scores $55,56,57,58$ and 59 and all other intervals are arranged in a like manner. If 55 is made the midpoint instead of the lower limit of a class interval, which includes scores 53, 54, 55, 56 and 57 , and a like change is made in the position of all intervals, then we have the distribution given in Table 1, Part 3.

It is evident that by using the same interval but changing its position as we have done the modes have been brought nearer together. We still have two "surprisingly pronounced modes" but they are fifty per cent. closer together; that is, they are now sepa. rated by five points instead of ten as before. It is evident that a change in mode has accompanied the change in position of the class intervals. It is our purpose now to change the size of the interval. The authors have grouped five scores together in a class. There is no valid statistical reason why data should be grouped in intervals of five. To illustrate this point the data are grouped in class intervals of eight in Table I, Part 4. No attempt will be made to justify the use of a class interval of eight with these data because this example is given merely to show how unstable the modal value is.

Here the modes for the two sexes are at the same interval, the boys having a frequency of Io and the girls a frequency of 8 . The conclusions concerning sex differences made by the authors on the basis of the modes shown in Table I, Part 2, lose half of their

'H. O. Ruga. Statiistical Methods Applied to Education. Page ror. 
significance when the data are rearranged as in Table I, Part 3 , and lose all of their statistical basis when the data are arranged in other class intervals as in Table 1, Part 4 . Hence, it seems fair to conclude that generalizations made on the basis of modal value have no sound statistical value.

Other averages have been computed for these data and a comparative table of their value is given below.

Arithmetic mean. $\quad P . E$.

$\begin{array}{lll}\text { Boyss, } \ldots \ldots \ldots \ldots \ldots \ldots & 63.9 & 1.24 \\ \text { Girls, } \ldots \ldots \ldots \ldots \ldots & 60.8 & 1.43\end{array}$

Difference. ...... 3.I

\begin{tabular}{|c|c|c|}
\hline ( & Median. & P.E. \\
\hline$\ldots \ldots \ldots$ & $59 \cdot 7$ & I.79 \\
\hline Difference, & 6.1 & \\
\hline
\end{tabular}

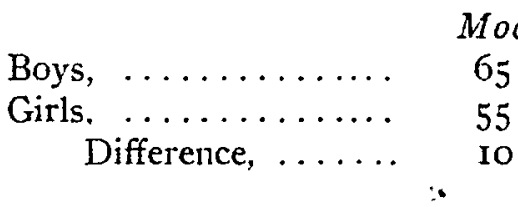

It appears from the above that no pronounced sex difference is shown. On the basis of the arithnetic mean or the refined median this difference is slight when the P.E. is taken into consideration.

Two interesting questions can be asked from the standpoint of statistics. (I) Is it fair to make conclusions concerning general differences in mental ability, as judged by the point scale, on the basis of a 3.I difference in arithmetic mean? (2) Is the point scale method so refined that one can be sure that the P.E. might not be greater than any of the above differences?

The second point concerning the statistical basis of the conclusions we are dealing with has to do with the number of cases considered. Turning to Table I, Part 2, we find that the modal point for the girls is the 55 point class, and that 8 girls and 2 boys receive such a score. In the same manner it can be shown that a majority of 7 boys are found at their modal point. It is obvious, then, that the conclusions concerning sex differences are made on the basis of 6 girls and 7 boys. 
The authors were evidently justified in making their conclusions on the basis of the arrangement of the data as given in the monograph and were also conscious of the limited number of cases considered; but it appears from the rearrangement of the data that no differences between the sexes, as great as indicated bv Yerkes, exist. 